\title{
Sulfonated Triterpenoid Saponins from Fagonia indica
}

Kamel H. Shaker ${ }^{\mathrm{a}}$, Mirko Bernhardt ${ }^{\mathrm{a}}$, M. Hani A. Elgamal ${ }^{\mathrm{b}}$ and

Karlheinz Seifert ${ }^{\mathrm{a}, *}$

a University of Bayreuth, Organic Chemistry I/2, NW II, D-95440 Bayreuth, Germany.

Fax: 49-921-555358. E-mail: karlheinz.seifert@uni-bayreuth.de

b National Research Centre, Laboratory of Natural Products, Dokki-Cairo, Egypt

* Author for correspondence and reprint requests

Z. Naturforsch. 55c, 520-523 (2000); received April 5, 2000

Fagonia indica, Triterpenoid Saponins, Indicasaponin C and D

Two new triterpenoid saponins, 3- $O$ - $\{[\beta$-D-4- $O$-sulfonylglucopyranosyl- $(1 \rightarrow 3)]-\alpha$-L-ara-

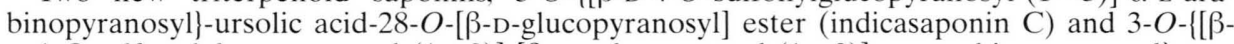
D-4- $O$-sulfonylglucopyranosyl- $(1 \rightarrow 3)]$-[ $\beta$-D-xylopyranosyl- $(1 \rightarrow 2)]-\alpha$-L-arabinopyranosyl $\}$ ursolic acid-28-O-[ $\beta$-D-glucopyranosyl] ester (indicasaponin $\mathrm{D})$ have been isolated from Fagonia indica. The structures were determined primarily by NMR spectroscopy. The assignment of NMR signals was performed by means of ${ }^{1} \mathrm{H}-{ }^{1} \mathrm{H}$ COSY, NOESY, ROESY, TOCSY, HMQC and HMBC experiments.

\section{Introduction}

Fagonia indica Brum. fil. belongs to the family Zygophyllaceae and is widely distributed in Egypt and Pakistan. The sapogenins oleanolic acid, betulic acid (Rizk et al., 1972), hederagenin and ursolic acid (Rahman and Ansari, 1984) could be detected after hydrolysis of the EtOH extract of the aerial parts of $F$. indica. Two taraxast-20-en-28-oic acid saponins have been isolated from $F$. indica (Ansari et al., 1987). In the course of our investigations on saponins of this plant we have obtained two ursolic acid and two oleanolic acid saponins (Shaker et al., 1999). In this report, we present the isolation and structure elucidation of two new sulfonated triterpenoid saponins.

\section{Results and Discussion}

The butanol extract of the whole plants of $F$. indica were obtained as described in the experimental section. The crude saponins were chromatographed by column chromatography on silica gel to be eluted successively with $\mathrm{CHCl}_{3}, \mathrm{CHCl}_{3}-$ $\mathrm{MeOH}$ and $\mathrm{CHCl}_{3}-\mathrm{MeOH}-\mathrm{H}_{2} \mathrm{O}$ with increasing amounts of $\mathrm{MeOH}$ and $\mathrm{H}_{2} \mathrm{O}$. The saponins $\mathbf{1}$ and $\mathbf{2}$ have been isolated after further purification by column chromatography on Sephadex LH-20 followed by preparative HPLC on RP-18 material.

The LSI mass spectrum of $\mathbf{1}$ exhibited the [M-1] $]^{-}$ion at $m / z$ 991. The fragment ions at $m / z 829$ [M-1-162] $^{-}$and $m / z 587$ [M-1-162-242] $^{-}$ showed the loss of a hexose moiety and hexose plus sulfonylhexose moiety. The fragment ion at $\mathrm{m} / \mathrm{z} 455$ [M-1-162-242-132] $]^{-}$indicated the elimination of a hexose plus sulfonylhexose plus pentose moiety. The $-\mathrm{OSO}_{3} \mathrm{H}$ group was characterized by the fragments $m / z 97\left[\mathrm{SO}_{4} \mathrm{H}\right]^{-}$and $\mathrm{m} / z$ $80\left[\mathrm{SO}_{3}\right]^{-}$. The $[\mathrm{M}-1]^{-}$ion together with ${ }^{1} \mathrm{H}$ and ${ }^{13} \mathrm{C}$ NMR data allowed us to propose the molecular formula $\mathrm{C}_{47} \mathrm{H}_{76} \mathrm{O}_{20} \mathrm{~S}$.

The ${ }^{1} \mathrm{H}$ and ${ }^{13} \mathrm{C}$ NMR spectra of $\mathbf{1}$ showed the presence of ursolic acid as aglycone. The signals of the axial and equatorial oriented protons of the ursolic acid were assigned by ROESY experiments. Three anomeric proton signals at $\delta 4.26$ $\left({ }^{3} \mathrm{~J}=7.6 \mathrm{~Hz}\right), 4.58\left({ }^{3} \mathrm{~J}=7.8 \mathrm{~Hz}\right)$, and $5.32\left({ }^{3} \mathrm{~J}=\right.$ $8.2 \mathrm{~Hz}$ ) indicated the presence of three saccharide units, one bonded as a glycosylester $(\delta 5.32)$ and the two others as glycosides $(\delta 4.26,4.58)$. By use of the coupling constants of the anomeric protons $\left({ }^{3} \mathrm{~J}=7.6-8.2 \mathrm{~Hz}\right),{ }^{1} \mathrm{H}-{ }^{1} \mathrm{H}$ COSY-45 and TOCSY spectra and the determination of the $\mathrm{D}$-form for glucose and the L-form for arabinose (as described in the experimental section) the individual saccharides were identified as $\beta$-D-glucopyranose, $\beta$-D-4$O$-sulfonylglucopyranose and $\alpha$-L-arabinopyranose. The linkage of the arabinose and one glucose moiety to the aglycone was determined by means of HMBC spectra. The cross peaks of the ${ }^{3} J$ long range couplings between $\mathrm{H}-1^{\prime}$ arabinose $\rightarrow \mathrm{C}-3$ aglycone and $\mathrm{H}-1^{\prime \prime \prime \prime}$ glucosyl ester $\rightarrow \mathrm{C}-28$ aglycone indicated the points of linkage to the sapogenin. 

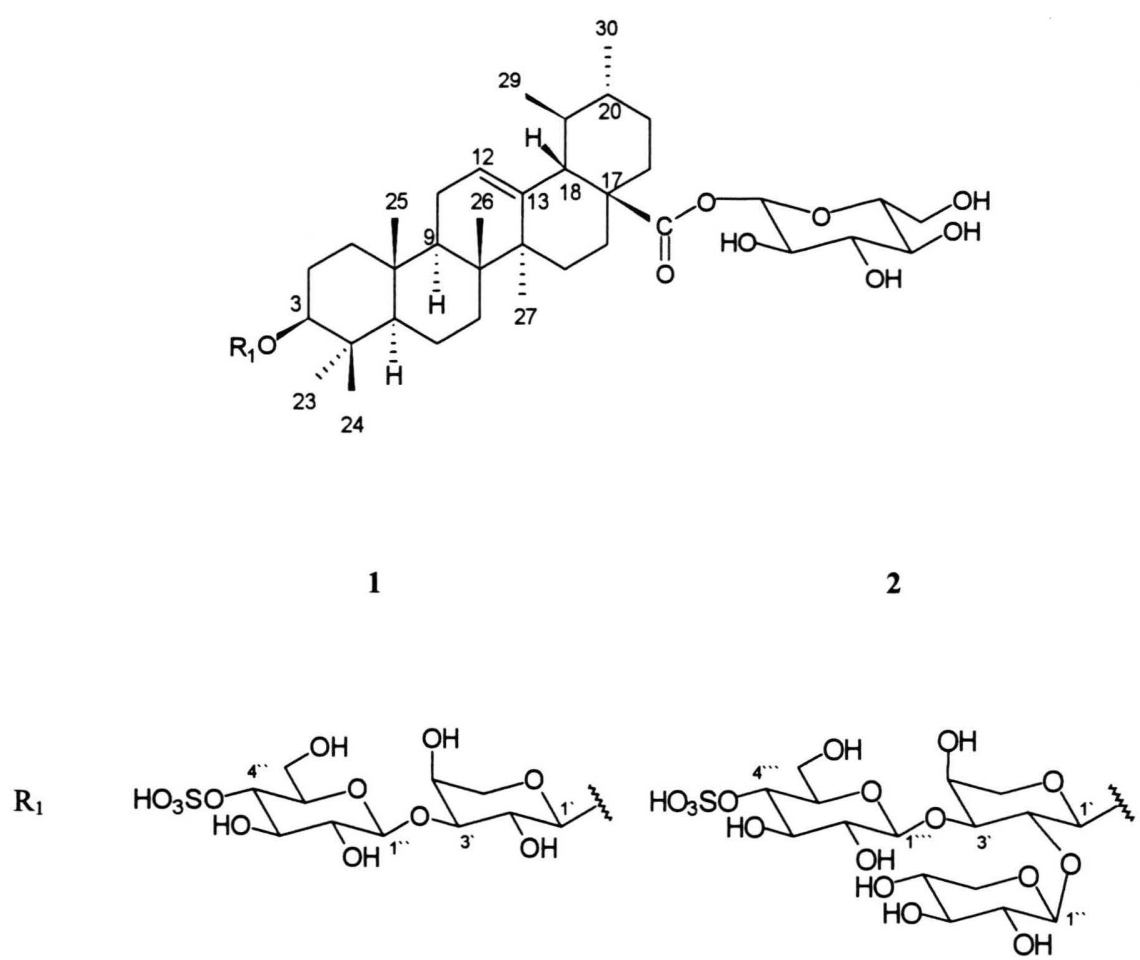

The HMBC cross peaks between $\mathrm{H}-1$ " 4-O-sulfonylglucopyranose $\rightarrow$ C-3' arabinose proved the interglycosidic linkage of 4- $O$-sulfonylglucopyranose at position C-3'. The downfield shifts of C-4" $-(\Delta \delta$ $+6.7)$ and $H-4$ "-signal $(\Delta \delta+0.82)$ of the sulfonated glucose of $\mathbf{1}$ in comparison with the glucose of the appropriate non sulfonated saponin were a proof for the sulfate group in position $4 "$.

The LSI mass spectrum of $\mathbf{2}$ exhibited the $[\mathrm{M}-1]^{-}$ion at $m / z$ 1123. This together with ${ }^{1} \mathrm{H}$ and ${ }^{13} \mathrm{C}$ NMR data led to the molecular formula $\mathrm{C}_{52} \mathrm{H}_{84} \mathrm{O}_{24} \mathrm{~S}$. The $[\mathrm{M}-1]^{-}$ion and the fragment ions at $\mathrm{m} / \mathrm{z} 961[\mathrm{M}-1-162]^{-}, \mathrm{m} / \mathrm{z} 829[\mathrm{M}-1-162-$ $132]^{-}, m / z 719[\mathrm{M}-1-162-242]^{-}, \mathrm{m} / z$ 587 [M-1$162-242-132]^{-}$and $m / z \quad 455 \quad[\mathrm{M}-1-162-242-$ $2 \times 132]^{-}$of $\mathbf{2}$ showed an additional pentose moiety compared with $\mathbf{1}$.

The ${ }^{1} \mathrm{H}$ and ${ }^{13} \mathrm{C}$ NMR data of $\mathbf{2}$ were in agreement with those of $\mathbf{1}$ referring to the aglycone ursolic acid. One additional anomeric proton signal at $\delta 4.69\left({ }^{3} J=6.5 \mathrm{~Hz}\right)$ showed a further pentose unit. The coupling constants ${ }^{3} J_{1^{\prime \prime \prime}, 2^{\prime \prime \prime}}=6.5 \mathrm{~Hz}$, ${ }^{3} J_{2^{\prime \prime \prime}, 3^{\prime \prime \prime}}={ }^{3} J_{3^{\prime \prime \prime}, 4^{\prime \prime \prime}}={ }^{3} J_{4^{\prime \prime \prime}, 5 \mathrm{ax}}{ }^{\prime \prime \prime}=9.3 \mathrm{~Hz}$ and ${ }^{3} J_{4^{\prime \prime \prime}, 5 \mathrm{eq}}=$ $4.3 \mathrm{~Hz}$ proved the axial position of the protons $\mathrm{H}-1^{\prime \prime \prime}-\mathrm{H}-4^{\prime \prime \prime}$ and thus the presence of a $\beta$-xylopyra- nose. The D-form for xylose was determined as described in the experimental section. The HMBC cross peak $\mathrm{H}-1^{\prime \prime \prime}$ xylose/C-2' arabinose ( $\delta$ 4.69/ $\delta 77.5)$ and the downfield shifts of the arabinose signals $H-2^{\prime}(\Delta \delta+0.17)$ and $C-2^{\prime}(\Delta \delta+5.2)$ in comparison with 1 proved the linkage of xylose in position 2 of arabinose.

\section{Experimental}

\section{General}

Negative ion MS: MAT 8500 (Finnigan), matrix glycerol. NMR: $500.13 \mathrm{MHz}\left({ }^{1} \mathrm{H}\right)$ and $125.76 \mathrm{MHz}$ $\left({ }^{13} \mathrm{C}\right)$, reverse probehead, $\delta$ in ppm, solvent $\mathrm{CD}_{3} \mathrm{OD}, \mathrm{CD}_{3} \mathrm{OD}$ signals were used as int. standard $\left({ }^{1} \mathrm{H}: 3.30,{ }^{13} \mathrm{C}: 49.0\right)$, temp. $290 \mathrm{~K}$, NOESY: phase-sensitive using TPPI, mixing time 300 and $600 \mathrm{msec}$, TOCSY: phase-sensitive using TPPI, mixing time $134.3 \mathrm{msec}$ ( $80 \mathrm{MLEV}-17$ cycles plus 2 trim pulses of $2.5 \mathrm{msec}$ each), HMQC: phasesensitive using TPPI, BIRD sequence, GARP decoupled, HMBC: using TPPI, delay to achieve long range couplings: $71 \mathrm{msec}\left(J_{\mathrm{C}, \mathrm{H}}=14 \mathrm{~Hz}\right)$.

CC: silica gel $(0.063-0.2 \mathrm{~mm})$; TLC: silica gel ( 0.25 and $1 \mathrm{~mm}$ precoated plates $60 \mathrm{~F}_{254}$, Merck, 
$0.25 \mathrm{~mm}$ precoated plastic sheets SIL G/UV 254 Macherey-Nagel), the spots were sprayed with 'triterpene reagent' ( $1 \%$ soln. of vanillin in $50 \%$ $\mathrm{H}_{3} \mathrm{PO}_{4}$ ), 'sugar reagent' (4\% ethanolic aniline$4 \%$ ethanolic diphenylamine $\left.-\mathrm{H}_{3} \mathrm{PO}_{4}, 5: 5: 1 \mathrm{v} / \mathrm{v}\right)$ and phosphomolybdic acid reagent (Aldrich). For the preparative HPLC a Knauer HPLC system equipped with a variable wavelength monitor together with LiChroprep RP-18 $(250 \times 8 \mathrm{~mm}, 5 \mu \mathrm{m}$, Knauer) prepacked column was used. GLC $\left(\mathrm{H}_{2}\right.$ at $50 \mathrm{kPa} ; 3 \min 80^{\circ}, 80-120^{\circ}$ with $3^{\circ} \mathrm{min}^{-1}, 120-$ $170^{\circ}$ with $0.5^{\circ} \mathrm{min}^{-1} 170-280^{\circ}$ with $5^{\circ} \mathrm{min}^{-1}$ ) was carried out on a Fisons GC 8130 instrument using a fused silica capillary column coated with DB 1 phase $(30 \mathrm{~m} \times 0.32 \mathrm{~mm}, \mathrm{~J} \& \mathrm{~W})$.

\section{Isolation}

F. indica was collected in 1996 near Hurghada Egypt and identified by Dr. M. Elgebaly from the National Research Centre (NRC) Cairo. A voucher specimen of the plant is deposited at the Herbarium of the NRC, Department of Chemotaxonomy. Dried powder of the whole plant of F. indica $(4 \mathrm{~kg})$ was exhaustively extracted with $80 \% \mathrm{MeOH}$. After removal of the solvent by evaporation, the residue was successively partitioned between $\mathrm{H}_{2} \mathrm{O}$ and $n$-BuOH. The butanolic fr. was evaporated under red. pres. at $50{ }^{\circ} \mathrm{C}$ to obtain a crude saponin mixture ( $25 \mathrm{~g})$. CC on silica gel eluting with $\mathrm{CHCl}_{3}-\mathrm{MeOH}-\mathrm{H}_{2} \mathrm{O}$ with increasing amounts of $\mathrm{MeOH}$ and $\mathrm{H}_{2} \mathrm{O}$ gave three frs.: $\mathrm{I}(3 \mathrm{~g})$, II $(5 \mathrm{~g})$ and III $(10 \mathrm{~g})$. I was further chromatographed by means of Sephadex LH-20 eluting with $\mathrm{MeOH}-\mathrm{H}_{2} \mathrm{O}$ 17:3 v/v and yielded three frs.: IV $(1.1 \mathrm{~g}), \mathrm{V}(1.2 \mathrm{~g})$ and VI (100 mg). Prep. HPLC (isocratic, $31 \% \mathrm{MeCN}$ in $\mathrm{H}_{2} \mathrm{O}$ ) of $100 \mathrm{mg}$ of fr. $\mathrm{V}$ gave pure saponins $\mathbf{1}(5 \mathrm{mg})$ and $\mathbf{2}(8 \mathrm{mg})$.

\section{(R)-2-Butylglycosides}

A sample (ca. $250 \mu \mathrm{g}$ ) of the appropriate saponin was hydrolysed with $0.5 \mathrm{ml} 5 \% \mathrm{HCl}$ for at least $3 \mathrm{~h}$ at $80^{\circ} \mathrm{C}$. After evaporation of the acid under red. pres., $0.5 \mathrm{ml}(R)-2-\mathrm{BuOH}$ was added, dried $\mathrm{HCl}$ gas was bubbled through the soln. for $30 \mathrm{~s}$ and the reaction mixture was heated for $3 \mathrm{~h}$ at $80^{\circ} \mathrm{C}$ under $\mathrm{N}_{2}$ in a sealed vessel. Trimethylsilylation was performed with $N$-methyl- $N$-trimethylsilyltrifluoroacetamide overnight. (R)-2-butyl-LAra: $R_{\mathrm{t}} 39.45, R_{\mathrm{i}} 1777 ;(R)-2$-butyl-D-Ara: $R_{\mathrm{t}} 38.42$ ，
$R_{\mathrm{i}} 1765 ;(R)$-2-butyl-L-Xyl: $R_{\mathrm{t}} 39.21, R_{\mathrm{i}} 1768 ;(R)-$ 2-butyl-D-Xyl: $R_{\mathrm{t}} 38.12, R_{\mathrm{i}} 1751$; $(R)$-2-butyl-L-Glc: $R_{\mathrm{t}} 81.92, R_{\mathrm{i}}$ 2086; $(R)$-2-butyl-D-Glc: $R_{\mathrm{t}} 82.25, R_{\mathrm{i}}$ 2088. Identification of the sugars were done by comparison of the $R_{\mathrm{i}}$ values and co-injection with the appropriate standard. $R_{\mathrm{i}}$ according to (van den Dool and Kratz, 1963). Consequently it was shown for the two saponins that arabinose belongs to the L-, glucose and xylose to the D-series.

\section{Spectroscopic data}

Indicasaponin $C(\mathbf{1}):\left(\mathrm{C}_{47} \mathrm{H}_{76} \mathrm{O}_{20} \mathrm{~S}, M_{\mathrm{r}}\right.$ 992); amorphous powder; $[\alpha]_{D}^{25}+18(\mathrm{MeOH} ; \mathrm{c} 0.15)$. LSIMS negative ion mode $\mathrm{m} / \mathrm{z}$ (rel. int.): $991[\mathrm{M}-1]^{-}$ (50), $829[\mathrm{M}-1-162]^{-}(10), 587\left[_{\mathrm{M}-1-162-242]^{-}}\right.$ (12), $455[\mathrm{M}-1-162-242-132]^{-}(8), 97\left[\mathrm{SO}_{4} \mathrm{H}\right]^{-}$ (100), $80\left[\mathrm{SO}_{3}\right]^{-}$(79). ${ }^{1} \mathrm{H}$ NMR and ${ }^{13} \mathrm{C}$ NMR: Tables I and II.

Table I. ${ }^{1} \mathrm{H}$ and ${ }^{13} \mathrm{C}$ NMR spectral data for the aglyca of saponins $\mathbf{1}$ and $\mathbf{2}$ in $\mathrm{CD}_{3} \mathrm{OD}$.

\begin{tabular}{|c|c|c|c|c|}
\hline & \multicolumn{2}{|c|}{1} & \multicolumn{2}{|c|}{2} \\
\hline & ${ }^{1} \mathrm{H}$ ax/eq & ${ }^{13} \mathrm{C}$ & ${ }^{1} \mathrm{H}$ ax/eq & ${ }^{13} \mathrm{C}$ \\
\hline 1 & $0.98 / 1.39$ & 40.0 & $0.99 / 1.38$ & 39.9 \\
\hline 2 & $1.73 / 1.82$ & 27.3 & $1.74 / 1.81$ & 27.3 \\
\hline 3 & 3.10 & 90.7 & 3.10 & 91.3 \\
\hline 4 & - & 40.4 & - & 40.3 \\
\hline 5 & 0.76 & 57.0 & 0.75 & 57.1 \\
\hline 6 & $1.38 / 1.52$ & 19.0 & $1.38 / 1.51$ & 19.1 \\
\hline 7 & $1.50 / 1.37$ & 34.2 & $1.50 / 1.37$ & 34.2 \\
\hline 8 & - & 41.1 & - & 41.0 \\
\hline 9 & 1.52 & 49.0 & 1.52 & 49.0 \\
\hline 10 & - & 38.0 & - & 37.8 \\
\hline 11 & $1.90 / 2.01$ & 23.8 & $1.90 / 1.99$ & 23.7 \\
\hline 12 & 5.23 & 127.3 & 5.23 & 127.2 \\
\hline 13 & - & 138.9 & - & 138.9 \\
\hline 14 & - & 43.4 & - & 43.2 \\
\hline 15 & $1.91 / 1.10$ & 29.2 & $1.91 / 1.11$ & 29.2 \\
\hline 16 & $2.14 / 1.78$ & 24.1 & $2.14 / 1.78$ & 24.3 \\
\hline 17 & - & 49.0 & - & 49.0 \\
\hline 18 & $\begin{array}{l}2.21 \mathrm{~d} \\
11.5 \mathrm{~Hz}\end{array}$ & 54.3 & $\begin{array}{l}2.21 d \\
11.5 \mathrm{~Hz}\end{array}$ & 54.1 \\
\hline 19 & 1.39 & 40.4 & 1.40 & 40.4 \\
\hline 20 & 0.98 & 40.9 & 0.98 & 40.5 \\
\hline 21 & $1.26 / 1.38$ & 30.9 & $1.26 / 1.38$ & 30.8 \\
\hline 22 & $1.75 / 1.65$ & 37.5 & $1.75 / 1.65$ & 37.4 \\
\hline 23 & $1.04 \mathrm{~s}$ & 28.2 & $1.04 \mathrm{~s}$ & 28.2 \\
\hline 24 & $0.83 s$ & 17.2 & $0.83 s$ & 16.7 \\
\hline 25 & $0.96 s$ & 16.3 & $0.95 s$ & 16.2 \\
\hline 26 & $0.82 s$ & 17.8 & $0.82 s$ & 17.7 \\
\hline 27 & $1.10 \mathrm{~s}$ & 24.1 & $1.11 \mathrm{~s}$ & 24.0 \\
\hline 28 & - & 177.9 & - & 177.9 \\
\hline 29 & $\begin{array}{l}0.88 d \\
6.6 \mathrm{~Hz}\end{array}$ & 18.0 & $\begin{array}{l}0.88 d \\
6.6 \mathrm{~Hz}\end{array}$ & 17.9 \\
\hline 30 & $\begin{array}{l}1.31 \mathrm{~d} \\
6.0 \mathrm{~Hz}\end{array}$ & 21.7 & $\begin{array}{l}1.32 \mathrm{~d} \\
6.0 \mathrm{~Hz}\end{array}$ & 21.6 \\
\hline
\end{tabular}


Table II. ${ }^{1} \mathrm{H}$ and ${ }^{13} \mathrm{C}$ NMR spectral data for the sugar moieties of saponins $\mathbf{1}$ and $\mathbf{2}$ in $\mathrm{CD}_{3} \mathrm{OD}$.

\begin{tabular}{|c|c|c|c|c|}
\hline & 1 & & 2 & \\
\hline & ${ }^{1} \mathrm{H}$ & ${ }^{13} \mathrm{C}$ & ${ }^{1} \mathrm{H}$ & ${ }^{13} \mathrm{C}$ \\
\hline Arc & & & & \\
\hline $\begin{array}{l}1^{\prime} \\
2^{\prime} \\
3^{\prime} \\
4^{\prime} \\
5^{\prime}\end{array}$ & $\begin{array}{l}4.26 d 7.6 \mathrm{~Hz} \\
3.68 \\
3.62 \\
4.02 \\
3.54 \mathrm{ax} \\
3.82 \mathrm{eq}\end{array}$ & $\begin{array}{r}107.3 \\
72.3 \\
84.1 \\
69.8 \\
66.9\end{array}$ & $\begin{array}{l}4.35 d 6.7 \mathrm{~Hz} \\
3.85 \\
3.80 \\
4.05 \\
3.51 \text { ax } \\
3.82 \mathrm{eq}\end{array}$ & $\begin{array}{r}106.2 \\
77.5 \\
83.8 \\
69.8 \\
66.4\end{array}$ \\
\hline Glc & & & & \\
\hline $\begin{array}{l}1^{\prime \prime} \\
2^{\prime \prime} \\
3^{\prime \prime} \\
4^{\prime \prime} \\
5^{\prime \prime} \\
6^{\prime \prime}\end{array}$ & $\begin{array}{l}4.58 d 7.8 \mathrm{~Hz} \\
3.39 \\
3.66 \\
4.13 \\
3.42 \\
3.84 / 3.72\end{array}$ & $\begin{array}{r}105.3 \\
75.4 \\
76.3 \\
77.6 \\
78.4 \\
62.5\end{array}$ & $\begin{array}{l}4.63 d 7.7 \mathrm{~Hz} \\
3.42 \\
3.64 \\
4.12 \\
3.45 \\
3.85 / 3.72\end{array}$ & $\begin{array}{r}104.8 \\
76.0 \\
76.5 \\
77.5 \\
78.2 \\
62.2\end{array}$ \\
\hline$X y$ & & & & \\
\hline $\begin{array}{l}1^{\prime \prime \prime} \\
2^{\prime \prime \prime} \\
3^{\prime \prime \prime} \\
4^{\prime \prime \prime} \\
5^{\prime \prime \prime}\end{array}$ & & & $\begin{array}{l}4.69 d 6.5 \mathrm{~Hz} \\
3.08 \\
3.25 \\
3.40 \\
3.12 \mathrm{ax} \\
3.78 \mathrm{eq}\end{array}$ & $\begin{array}{r}104.8 \\
76.2 \\
78.5 \\
70.9 \\
67.1\end{array}$ \\
\hline 28 & & & & \\
\hline $\begin{array}{l}1^{\prime \prime \prime \prime} \\
2^{\prime \prime \prime \prime} \\
3^{\prime \prime \prime \prime} \\
4^{\prime \prime \prime \prime} \\
5^{\prime \prime \prime \prime} \\
6^{\prime \prime \prime \prime \prime}\end{array}$ & $\begin{array}{l}5.32 d 8.2 \mathrm{~Hz} \\
3.31 \\
3.39 \\
3.33 \\
3.37 \\
3.81 / 3.68\end{array}$ & $\begin{array}{l}95.8 \\
73.6 \\
78.6 \\
71.6 \\
78.3 \\
62.4\end{array}$ & $\begin{array}{l}5.32 \mathrm{~d} 8.2 \mathrm{~Hz} \\
3.29 \\
3.39 \\
3.32 \\
3.38 \\
3.81 / 3.68\end{array}$ & $\begin{array}{l}95.6 \\
73.8 \\
78.0 \\
71.4 \\
78.3 \\
62.1\end{array}$ \\
\hline
\end{tabular}

Ansari A. A., Kenne L. and Rahman A. U. (1987), Isolation and characterization of two saponins from Fagonia indica. Phytochemistry 26, 1487-1490.

van den Dool H. and Kratz, P. D. (1963), A generalization of the retention index system including linear temperature programmed gas-liquid partition chromatography. J. Chromatog. 11, 463-471.

Rahman A. U. and Ansari A. A. (1984), Hederagenin, ursolic acid, and pinatol from Fagonia indica. J. Nat. Prod. 47, 186-187.
Indicasaponin $D$ (2): $\left(\mathrm{C}_{52} \mathrm{H}_{84} \mathrm{O}_{24} \mathrm{~S}, M_{\mathrm{r}} 1124\right)$; amorphous powder; $[\alpha]_{D}^{25}+27(\mathrm{MeOH}$; c 0.18$)$. LSIMS negative ion mode $\mathrm{m} / z$ (rel. int.): $1123[\mathrm{M}-1]^{-}$ (62), 961 [M-1-162 $]^{-}$(10), 829 [M-1-162-132]-, 719

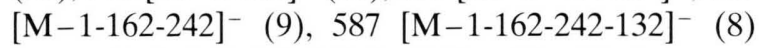
and $455[\mathrm{M}-1-162-242-2 \times 132]^{-}(8), 97\left[\mathrm{SO}_{4} \mathrm{H}\right]^{-}$ (100), $80\left[\mathrm{SO}_{3}\right]^{-}$(79). ${ }^{1} \mathrm{H}$ NMR and ${ }^{13} \mathrm{C}$ NMR: Tables I and II.

\section{Acknowledgement}

Support of this research by a grant of the Deutsche Forschungsgemeinschaft (Se 595/7-1, 7-2) is gratefully acknowledged.
Rizk A. M., Hammouda F. M. and Abdel-Gawad M. M. (1972), The triterpenoid sapogenins of Fagonia indica Brum.. Pharmazie 27, 534-535.

Shaker K. H., Bernhardt M., Elgamal M. H. A. and Seifert, K. (1999), Triterpenoid saponins from Fagonia indica. Phytochemistry 51, 1049-1053. 